\title{
D-Serine and D-Cycloserine Reduce Compulsive Alcohol Intake in Rats
}

\author{
Taban Seif', Jeffrey A Simms', Kelly Lei', Scott Wegner', Antonello Bonci ${ }^{2,3}$, Robert O Messing ${ }^{1,4}$ and \\ F Woodward Hopf ${ }^{*}, 1$
}

'Department of Neurology, University of California at San Francisco, San Francisco, CA, USA; ${ }^{2}$ NIDA Intramural Research Program, Baltimore, MD, USA; ${ }^{3}$ Solomon H. Snyder Department of Neuroscience, The Johns Hopkins University, School of Medicine, Baltimore, MD, USA;

${ }^{4}$ The University of Texas at Austin, College of Pharmacy, Austin, TX, USA

\begin{abstract}
There is considerable interest in NMDAR modulators to enhance memory and treat neuropsychiatric disorders such as addiction, depression, and schizophrenia. D-serine and D-cycloserine, the NMDAR activators at the glycine site, are of particular interest because they have been used in humans without serious adverse effects. Interestingly, D-serine also inhibits some NMDARs active at hyperpolarized potentials (HA-NMDARs), and we previously found that HA-NMDARs within the nucleus accumbens core (NAcore) are critical for promoting compulsion-like alcohol drinking, where rats consume alcohol despite pairing with an aversive stimulus such as quinine, a paradigm considered to model compulsive aspects of human alcohol use disorders (AUDs). Here, we examined the impact of D-serine and D-cycloserine on this aversion-resistant alcohol intake (that persists despite adulteration with quinine) and consumption of quinine-free alcohol. Systemic D-serine reduced aversion-resistant alcohol drinking, without altering consumption of quinine-free alcohol or saccharin with or without quinine. Importantly, D-serine within the NAcore but not the dorsolateral striatum also selectively reduced aversionresistant alcohol drinking. In addition, D-serine inhibited EPSCs evoked at $-70 \mathrm{mV}$ in vitro by optogenetic stimulation of $\mathrm{mPFC}-\mathrm{NAcore}$ terminals in alcohol-drinking rats, similar to reported effects of the NMDAR blocker AP5. Further, D-serine preexposure occluded AP5 inhibition of mPFC-evoked EPSCs, suggesting that D-serine reduced EPSCs by inhibiting HA-NMDARs. Systemic D-cycloserine also selectively reduced intake of quinine-adulterated alcohol, and D-cycloserine inhibited NAcore HA-NMDARs in vitro. Our results indicate that HA-NMDAR modulators can reduce aversion-resistant alcohol drinking, and support testing of D-serine and D-cycloserine as immediately accessible, FDA-approved drugs to treat AUDs.

Neuropsychopharmacology (2015) 40, 2357-2367; doi:I0.1038/npp.2015.84; published online 29 April 2015
\end{abstract}

\section{INTRODUCTION}

The compulsion to drink alcohol despite significant adverse social, physical, and legal consequences is a pernicious obstacle to treating alcohol use disorders (AUDs) (Anton, 2000; Koob and Volkow, 2010; Modell et al, 1992). Because existing pharmacotherapies are moderately efficacious or act only in a subset of AUD patients (Spanagel, 2009), there is a critical need to better understand the mechanisms driving compulsive intake in order to improve treatment. Procedures in which animals voluntary self-administer alcohol despite pairing it with aversive stimuli provide models to study and potentially intervene in this aversion-resistant, compulsionlike drinking. For example, we found that, following $\sim 3$ months of intermittent alcohol intake, rats continue to drink alcohol despite pairing intake with footshocks or the

\footnotetext{
*Correspondence: Dr FW Hopf, Department of Neurology, University of California at San Francisco, 675 Nelson Rising Lane, Room 490D, San Francisco, CA 94158, USA, Tel: + I 510418 1966, Fax: + I 415502 7332, E-mail: Frederic.Hopf@ucsf.edu

Received 21 October 20 I4; revised 13 March 2015; accepted 17 March 2015; accepted article preview online 24 March 2015
}

bitter-tastant quinine (Hopf et al, 2010; Seif et al, 2013). This aversion-resistant intake is considered to model compulsive aspects of human AUDs (Everitt and Robbins, 2005; Hopf and Lesscher, 2014; Hopf et al, 2010; Lesscher et al, 2010; Seif et al, 2013; Vengeliene et al, 2009).

The nucleus accumbens core (NAcore) integrates motivationally relevant stimuli to drive activity (Everitt and Robbins, 2005; Koob and Volkow, 2010) including aversion-related behavior (Roitman et al, 2005; Schwienbacher et al, 2004). We recently found that long-term, intermittent alcohol consumption in rats leads to appearance of unusual NMDA receptors that are active at hyperpolarized potentials (HA-NMDARs) within the NAcore (Seif et al, 2013). These HA-NMDARs are only observed under cortical inputs to NAcore, specifically from the medial prefrontal cortex (mPFC) and insula (Seif et al, 2013), regions that regulate addiction- and aversion-related behaviors (Everitt and Robbins, 2005; Koob and Volkow, 2010; Naqvi et al, 2014). Importantly, this HA-NMDAR/cortical-NAcore signaling is critical for promoting aversion-resistant alcohol drinking, but does not regulate alcohol drinking that is not explicitly paired with aversive consequences (Seif et al, 2013). In this regard, some clinical investigators (Naqvi et al, 2014; Tiffany 
and Conklin, 2000) have suggested that cortical regions are selectively recruited by the conflict associated with aversionresistant, compulsive intake, that is, between motivation to drink alcohol and the desire to avoid aversive consequences. In contrast, alcohol intake without overt adverse consequences would involve the striatum, with less requirement for cortical input. Thus, we propose that NAcore HANMDARs play a role in overcoming conflict associated with aversion-resistant intake, and thus represent a novel therapeutic target to counteract the compulsion to drink alcohol.

There has long been interest in using NMDAR modulators to address a number of human conditions, for example, to suppress the enhanced glutamatergic function associated with protracted alcohol consumption (Gass and Olive, 2008; Krystal et al, 2003, 2011; Spanagel, 2009), and to enhance memory as well as overcome decreased NMDAR function that may contribute to schizophrenia, Parkinson's disease, and cocaine addiction (D'Ascenzo et al, 2014; Heresco-Levy et al, 2013; Martineau et al, 2014; Sani et al, 2012; Tsai and Lin, 2010). Modulators of the NMDAR glycine site, such as $\mathrm{D}$-serine and D-cycloserine (DCS), are of particular interest because of their use in many patient populations with few side effects or safety issues noted (D'Ascenzo et al, 2014; D'Souza et al, 2013; Heresco-Levy et al, 2013; Kantrowitz et al, 2010; Tsai and Lin, 2010; but see Krug et al, 2007), and because the moderate NMDAR inhibition these reagents afford is considered more favorable than stronger NMDAR inhibitors that can have significant adverse effects (cf, Heresco-Levy et al, 2013; Millan, 2005).

Although D-serine is a canonical positive modulator of NMDARs (Cull-Candy and Leszkiewicz, 2004; Millan, 2005), it can also inhibit HA-NMDARs (Chatterton et al, 2002; Takarada et al, 2009, 2012). Here, we examined whether D-serine or DCS systemically, or D-serine within the NAcore, could suppress aversion-resistant alcohol intake. We also combined in vitro electrophysiology with optogenetics to address the molecular mechanism of D-serine and DCS. Together, our results support D-serine and DCS as immediately accessible pharmacological therapies to reduce compulsive drinking associated with AUDs.

\section{MATERIALS AND METHODS}

\section{Animal Handling}

All procedures followed the Guide for Care and Use of Laboratory Animals provided by the National Institutes of Health, and approval of the institutional animal care and use committee of UCSF. Adult male Wistar rats $(\sim 450-550 \mathrm{~g}$ at surgery) were individually housed with ad libitum access to food and water.

\section{Alcohol Drinking}

Rats learned to voluntarily consume alcohol through twobottle, home cage, intermittent access to $20 \%$ alcohol (IAA) as previously described (Hopf et al, 2010; Seif et al, 2013). Starting on Monday, Wednesday, and Friday late afternoons, rats had $16-20 \mathrm{~h}$ access to two bottles, one containing alcohol $(20 \% \mathrm{v} / \mathrm{v}$ with water) and the other water. After $\sim 10$ weeks of IAA, rats were switched to drink alcohol versus water under two-bottle choice for $20 \mathrm{~min} / \mathrm{day}, 5$ day/week in the late afternoon. Rat blood alcohol concentrations were $48.5 \pm 9.4 \mathrm{mg} / \mathrm{dl}$ for $0.97 \pm 0.09 \mathrm{~g} / \mathrm{kg}$ alcohol intake $(n=10)$, measured $30 \mathrm{~min}$ after starting access to alcohol (methods as in Carnicella et al, 2009). After $\sim 4$ weeks of $20 \mathrm{~min} /$ day access, and after intake had $<20 \%$ variability for 5 days, we tested alcohol intake with or without the bitter-tastant quinine (10 mg/l, 0.001\%, 25 $\mu \mathrm{M})(20 \mathrm{~min} /$ day, 5 day/week) or performed in vitro electrophysiology.

To minimize the possible contribution of habituation to the aversive properties of quinine across time, rats first had minimal initial habituation to alcohol+quinine (2-3 days). Importantly, rats then experienced the different experimental conditions (alcohol drinking with or without quinine, and with vehicle versus D-serine or DCS) in a randomized, counterbalanced manner using a Latin-Square design. Rats were therefore as likely to receive D-serine during the first alcohol-quinine session as they were to receive vehicle, and thus D-serine changes in alcohol drinking were unlikely to represent order effects or habituation to quinine across time. Also, rats always had at least 1 day of drinking alcohol without quinine and without drug treatment between experimental test days, avoiding any concerns related to drinking quininealcohol across successive days. D-serine, DCS, or saline was injected 15-20 min before access to alcohol.

\section{Saccharin Intake}

After $\sim 10$ weeks of IAA followed by $\sim 4$ weeks of access to alcohol for $20 \mathrm{~min} /$ day, 5 day/week, rats were switched to drinking saccharin \pm quinine versus water under two-bottle choice access for $20 \mathrm{~min} /$ day, 5 day/week in the late morning $(1100-1200 \mathrm{~h})$. These rats also drank alcohol (20 min/day) in the late afternoon. For the first experiment, rats drank one of four cocktails: $300 \mathrm{mg} / \mathrm{l}(0.03 \%, 1.65 \mathrm{mM})$ saccharin, $1330 \mathrm{mg} / \mathrm{l}$ saccharin $(0.13 \%, 7.3 \mathrm{mM}), 1330 \mathrm{mg} / \mathrm{l}$ saccharin $+10 \mathrm{mg} / \mathrm{l}$ quinine, or $1330 \mathrm{mg} / \mathrm{l}$ saccharin $+30 \mathrm{mg} / \mathrm{l}$ quinine (Seif et al, 2013). For the second experiment, rats drank $150 \mathrm{mg} / \mathrm{l}$ saccharin $(0.015 \%, 0.83 \mathrm{mM})$ or $300 \mathrm{mg} / \mathrm{l}$ saccharin $+10 \mathrm{mg} / \mathrm{l}$ quinine. Different conditions were randomized across and within rats, and across days, using a Latin-square design. Rats drank each concentration of saccharin \pm quinine at least 4 days before D-serine/DCS experiments.

\section{Surgery and Histology}

Surgical methods were as previously described (Seif et al, 2013). Rats were infected in the mPFC (for NAcore recording: $\mathrm{AP}+3.20, \mathrm{ML} \pm 1.20, \mathrm{DV}-3.00,10^{\circ}$ tilt; for DLS recording: same except DV -2.00 ) with $0.6 \mu \mathrm{l} /$ side of AAV-Camk2a-ChR2-EYFP $\sim 8$ weeks before in vitro experiments. Cannulae bilaterally targeted the medial NAcore (AP +2.20, $\mathrm{ML} \pm 2.70, \mathrm{DV}-6.18,8^{\circ}$ tilt) or DLS (AP +1.0, ML $\pm 3.6, \mathrm{DV}-4.0$ ), with the injector $1 \mathrm{mM}$ below cannulae tip during D-serine injection (in $0.6 \mu \mathrm{l}$, over $60 \mathrm{~s}$, then $60 \mathrm{~s}$ diffusion before removing the injector).

\section{In vitro Electrophysiology}

Methods, including slice preparation, were as previously described (Seif et al, 2013). Internal solution for excitatory postsynaptic currents (EPSCs) contained (in $\mathrm{mM}$ ): 120 
a

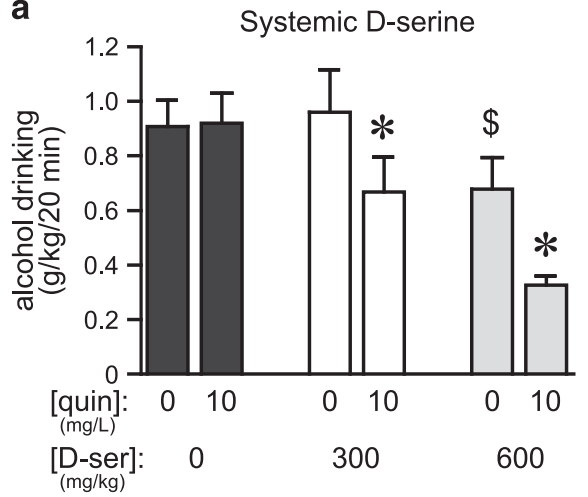

d
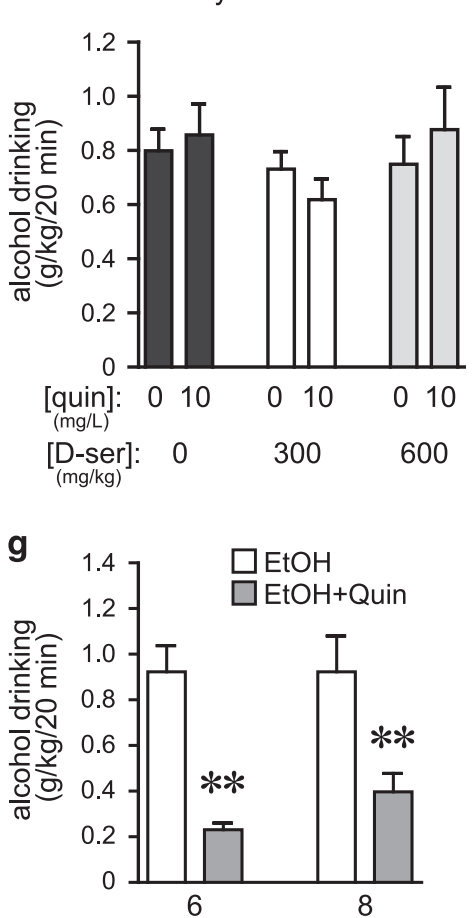

wk of IAA intake b

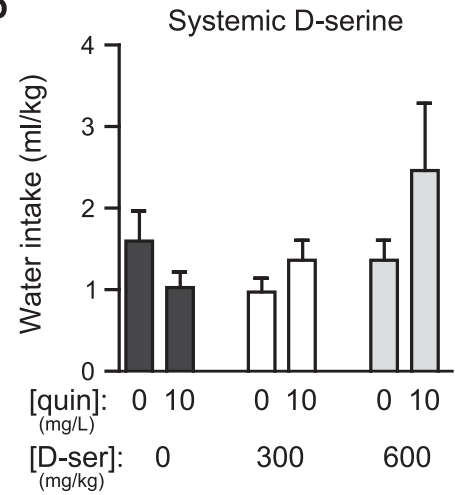

e

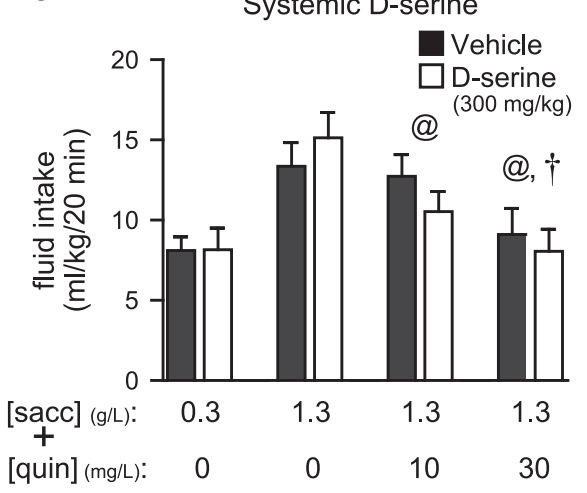

C

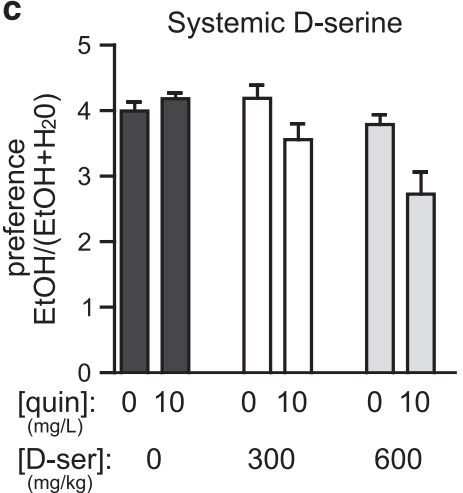

f
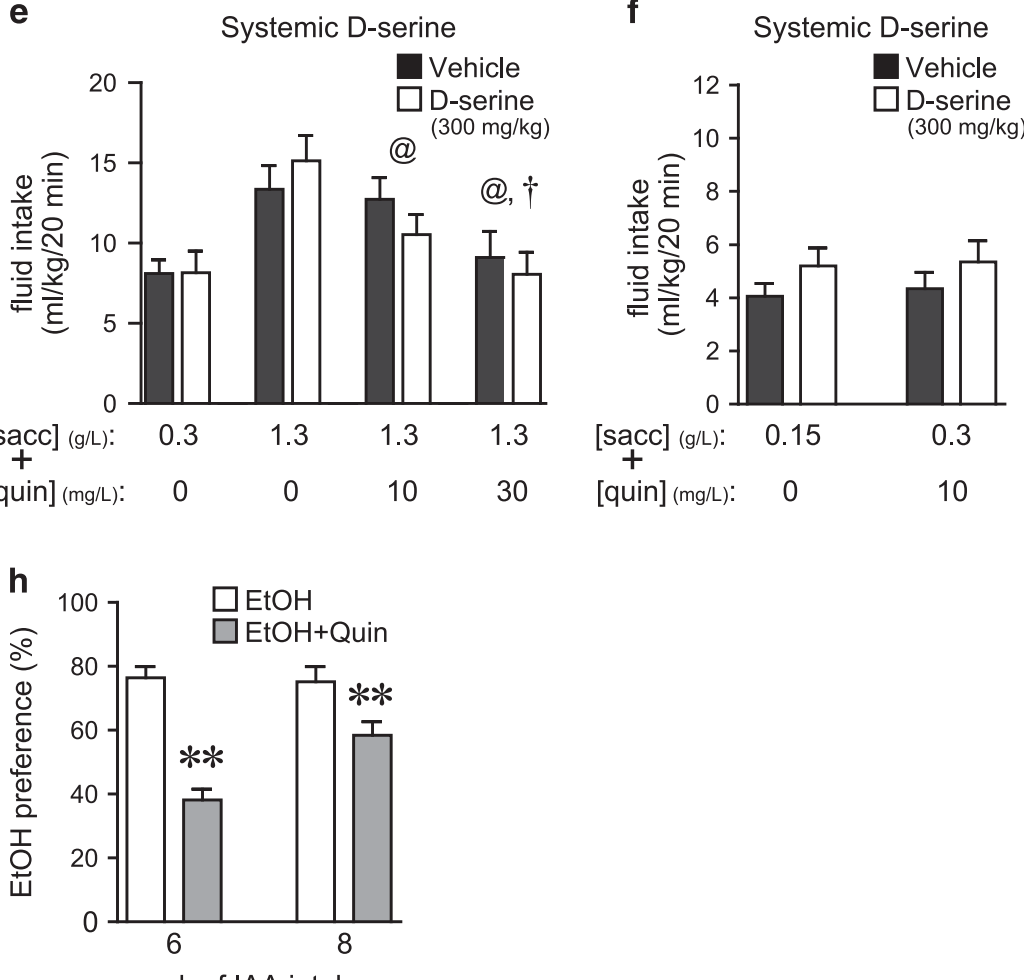

Figure I Systemic D-serine only reduced aversion-resistant alcohol consumption. (a) D-serine (i.p., $300 \mathrm{mg} / \mathrm{kg}$ ) reduced drinking of quinine-adulterated alcohol but not quinine-free alcohol (quinine: $F_{1,7}=20.675, p=0.003$; $D$-serine: $F_{1,14}=17.799, p=0.001$; interaction: $F_{1,14}=4.294, p=0.035$ ). $* p<0.05$ for quinine/D-serine-300 vs quinine/vehicle $(n=8)$. D-serine at $600 \mathrm{mg} / \mathrm{kg}$ reduced intake of both quinine-adulterated and quinine-free alcohol $(* p<0.05$ quininefree vs quinine conditions; ${ }^{\$} p<0.05 \mathrm{D}$-serine vs vehicle). (b, c) D-serine decreases in quinine-adulterated alcohol drinking were not accompanied by changes in water intake (b) (quinine: $F_{1,7}=1.926, p=0.208$; D-serine: $F_{1,14}=1.210, p=0.327$; interaction: $F_{1,14}=3.268, p=0.068$ ) but there were significant decreases in preference (alcohol intake/(alcohol+water intake)) (c) (quinine: $F_{1,7}=\mid 3.862, p=0.007$; D-serine: $F_{1,14}=|2.56|, p<0.00 \mid$; interaction: $F_{1,14}=3.3 \mid 3$, $p=0.066$ ). (d) $D$-serine treatment did not reduce alcohol intake the day after $D$-serine treatment (quinine: $F_{1,7}=0.099, p=0.763 ; D$-serine: $F_{1,14}=1.589$, $p=0.239$; interaction: $F_{1,14}=1.194, p=0.332$ ). (e) D-serine $(300 \mathrm{mg} / \mathrm{kg})$ did not alter intake of saccharin \pm quinine $(n=13$; saccharin-quinine doses: $F_{3,36}=27.837, p<0.00$ I; D-serine: $F_{1,36}=0.213, p=0.653$; interaction: $F_{3,36}=2.074, p=0.121$ ). Quinine significantly reduced intake of $\mid 330 \mathrm{~g} / \mathrm{l}$ saccharin $\left({ }^{@} p<0.0\right.$ I, sacc with vs without quin; ${ }^{\dagger} p<0.0 \mathrm{I}$, sacc with $10 \mathrm{vs} 30 \mathrm{mg} / \mathrm{l}$ quin). (f) D-serine $(300 \mathrm{mg} / \mathrm{kg}$ ) did not reduce, but instead slightly increased, consumption of lower saccharin concentrations $(150 \mathrm{mg} / \mathrm{l})$ or saccharin-quinine $\left(300 \mathrm{mg} / \mathrm{l}\right.$ sacc $+10 \mathrm{mg} / \mathrm{l}$ quin) $\left(n=\mid 4\right.$; saccharin \pm quinine: $F_{1,13}=0.64 \mid$, $p=0.770$; D-serine: $F_{1,13}=13.886, p=0.003$; interaction: $\left.F_{1,13}=0.035, p=0.854\right)$. $(g, h)$ After only 6 or 8 weeks of intermittent alcohol intake ( $n=17$ ), quinine adulteration $(30 \mathrm{mg} / \mathrm{l})$ significantly reduced alcohol intake $(\mathrm{g})\left( \pm\right.$ quinine: $\left.\mathrm{F}_{\mathrm{I}, 16}=26.727, p<0.00 \mathrm{I}\right)$ and preference $(\mathrm{h})\left( \pm\right.$ quinine: $\mathrm{F}_{\mathrm{I}, \mathrm{I}}=43.9 \mathrm{I} \mathrm{I}$, $p<0.00 \mathrm{I}$ ) (see also Hopf et al, 20 I0), whereas quinine adulteration did not reduce alcohol intake after $>$ I 2 weeks of intermittent intake (a). $* * p<0.0$ I. Sacc, saccharin; D-ser, D-serine; quin, quinine; veh, vehicle.

cesium-methanesulfonate, 20 HEPES, 0.4 EGTA, $2.8 \mathrm{NaCl}, 5$ TEA-Cl, $2.5 \mathrm{Mg}$-ATP, and 0.25 Na-GTP, pH 7.2-7.3. ACSF contained (in $\mathrm{mM}$ ): $126 \mathrm{NaCl}, 2.5 \mathrm{KCl}, 1.2 \mathrm{NaH}_{2} \mathrm{PO} 4,1.2$ $\mathrm{MgCl}_{2}, 2.4 \mathrm{CaCl}_{2}, 18 \mathrm{NaHCO}_{3}$, and 11 glucose, $\mathrm{pH}$ 7.2-7.4, 31-32 ${ }^{\circ} \mathrm{C}$. EPSCs were recorded using Clampex 10.1 and
Axon 700A amplifier (Molecular Devices, Foster City, CA), filtered at $2 \mathrm{kHz}$ and digitized at $10 \mathrm{kHz}$. Series and input resistance were monitored with a $4-\mathrm{mV}(50 \mathrm{~ms})$ depolarizing step $800 \mathrm{~ms}$ after every EPSC. Electrically evoked currents were elicited using a bipolar stimulating electrode $\sim 200 \mu \mathrm{M}$ 
dorsal to the patched neuron. ChR2-evoked EPSCs were elicited with an LED (Prizmatrix, $480 \mathrm{~nm}, 5 \mathrm{~ms}$ ). EPSC data were expressed as percent change from baseline, averaged during $5 \mathrm{~min}$ before drug application. For statistics, drug response was the average current across the last $3 \mathrm{~min}$ of drug application.

\section{Reagents}

AAV2-CamK2-ChR2-eYFP was from University of North Carolina, Chapel Hill Vector Core. Quinine hydrochloride, D-serine, and DCS were from Sigma-Aldrich (St Louis, MO). Saccharin sodium hydrate was from Acros Organics (Morris Plains, NJ).

\section{Statistical Analysis}

All data are shown as mean \pm SEM. D-serine and DCS behavioral results were normally distributed and evaluated by two-way repeated-measures ANOVA with repeated measures for \pm quinine and $\pm \mathrm{D}$-serine treatment, and Tukey's post hoc test. In vitro experiments were analyzed using an unpaired $t$-test for normally distributed data, and Mann-Whitney test or Friedman repeated-measures ANOVA on ranks for results that were not normally distributed. Statistical analyses were performed with SigmaPlot v13 (Systat Software, San Jose, CA).

\section{RESULTS}

\section{Systemic Administration of D-Serine Reduced Aversion- Resistant Alcohol Intake}

D-serine is an agonist at most NMDAR subunits, but can also inhibit HA-NMDARs (Chatterton et al, 2002; Takarada et al, $2009,2012)$. We recently showed that inhibiting NAcore HANMDARs selectively decreases aversion-resistant alcohol drinking, with no effect on intake not explicitly paired with aversive consequences (Seif et al, 2013). Thus, we hypothesized that D-serine would selectively suppress consumption of alcohol adulterated with $10 \mathrm{mg} / \mathrm{l}$ quinine. D-serine at $300 \mathrm{mg} / \mathrm{kg}$ (i.p.) significantly reduced drinking of quinineadulterated alcohol, with no effect on quinine-free alcohol intake (Figure 1a, $p<0.05$ post hoc). A higher D-serine dose $(600 \mathrm{mg} / \mathrm{kg})$ reduced alcohol consumption irrespective of whether or not quinine was present (Figure 1a), indicating more general effects at this dose (see also Lockridge et al, 2012). Decreased aversion-resistant drinking was not accompanied by significant changes in concurrent water intake (Figure 1b), or a significant quinine/D-serine interaction for alcohol preference (Figure 1c, see figure legend). In addition, alcohol drinking the day after testing was not different among groups, indicating no lasting effects of D-serine exposure on alcohol drinking (Figure 1d).

Alcohol can be perceived as sweet or sweet/bitter combined (Goodwin et al, 2000). As decreased consumption of quinine-adulterated alcohol might reflect changes in palatability, we next determined whether D-serine reduced intake of saccharin alone or combined with quinine. Quinine decreased intake of saccharin $(1330 \mathrm{mg} / \mathrm{l})$ in a dosedependent manner, but $\mathrm{D}$-serine $(300 \mathrm{mg} / \mathrm{kg})$ did not alter consumption of saccharin-quinine (Figure 1e). In a separate experiment, D-serine did not alter drinking of lower concentrations of saccharin-quinine or saccharin alone (Figure 1f) where drinking volumes were more similar to those during alcohol intake $(\sim 5-6 \mathrm{ml} / \mathrm{kg})$. Similar to alcohol sessions, concurrent water intake was low during saccharinquinine sessions, resulting in high preference values (not shown). Although $10 \mathrm{mg} / \mathrm{l}$ quinine more moderately reduced intake of $1330 \mathrm{mg} / \mathrm{l}$ saccharin, quinine decreased consumption of a lower saccharin dose $(300 \mathrm{mg} / \mathrm{l})$ by $\sim 50 \%$ $(p<0.001)$, confirming the aversive nature of this quinine concentration. In agreement, quinine adulteration significantly reduced alcohol drinking after only 6 or 8 weeks of intermittent alcohol intake (Figure $1 \mathrm{~g}$ and $\mathrm{h}$ ), concurring with our previous results that showed that aversion-resistant alcohol drinking develops after 12 weeks but not 6 weeks of intermittent intake (Hopf et al, 2010). Furthermore, quinine in water is highly aversive to alcohol-drinking rats at $1 \mathrm{mg} / \mathrm{l}$ quinine or greater (Hopf et al, 2010). Together, these results confirm that quinine concentrations used here were aversive to intermittent-drinking rats, supporting the conclusion that systemic D-serine specifically reduced aversion-resistant alcohol intake without altering taste palatability or general motor function.

\section{D-Serine within the NAcore Reduced Aversion-Resistant Alcohol Consumption}

We recently showed that inhibiting NAcore HA-NMDARs with the NMDAR blocker AP5, or by shRNA knockdown of the HA-NMDAR subunit GluN2c, selectively reduces aversion-resistant alcohol drinking (Seif et al, 2013). Thus, we locally infused D-serine (50 or $100 \mu \mathrm{g} /$ side; Fiorenza et al, 2012; Kretschmer and Schmidt, 1996) to determine whether the NAcore could mediate systemic D-serine effects on drinking. Intra-NAcore D-serine significantly reduced intake of quinine-adulterated alcohol but not quinine-free alcohol (Figure 2a), without significant changes in preference for the alcohol-quinine solution (Figure $2 \mathrm{c}$ and $\mathrm{d}$ ); the lack of significant changes in preference likely reflects the low water intake during the $20 \mathrm{~min}$ intake session. D-serine decreased consumption of quinine-adulterated alcohol by $39.9 \pm 11.9 \%$ (for $50 \mu \mathrm{g}$ ) and $61.5 \pm 7.6 \%$ (for $100 \mu \mathrm{g}$ ) relative to quininefree alcohol, indicating a substantial effect of NAcore D-serine on aversion-resistant intake. Alcohol drinking the day after testing did not differ among groups, indicating no lasting effects of D-serine on intake (Figure 2e). Also, in contrast to its effects in the NAcore, bilateral D-serine injection within the dorsolateral striatum (DLS) $(50 \mu \mathrm{g} / \mathrm{side})$ had no effect on intake of alcohol \pm quinine (Figure $2 \mathrm{f}$ and $\mathrm{g}$ ). Thus, the selective impact of systemic D-serine on aversion-resistant alcohol drinking likely required the NAcore but not the DLS.

\section{D-Serine Reduced NMDAR Function at $-70 \mathrm{mV}$ Resting Potential In vitro}

HA-NMDARs in the NAcore of alcohol-drinking rats promote aversion-resistant alcohol intake (Seif et al, 2013). As D-serine can inhibit HA-NMDARs (Chatterton et al, 2002; Takarada et al, 2009, 2012), we determined whether D-serine inhibited NAcore HA-NMDARs in vitro in alcoholdrinking rats. In particular, we examined EPSCs generated at $-70 \mathrm{mV}$ by ChR2 stimulation of $\mathrm{mPFC}-\mathrm{NAcore}$ inputs 
a

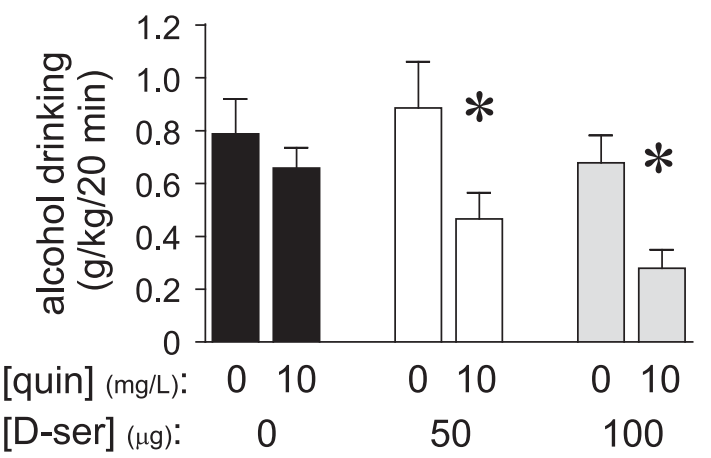

b

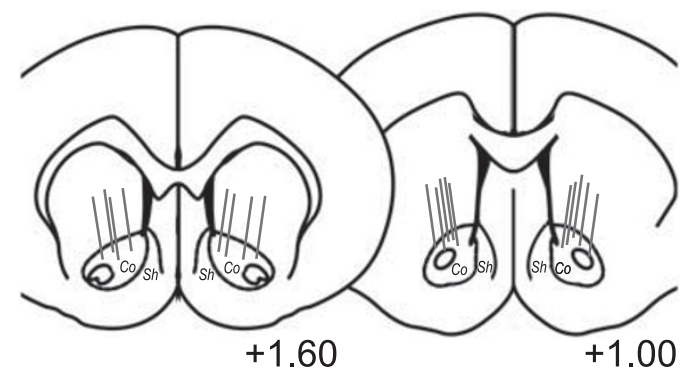

c

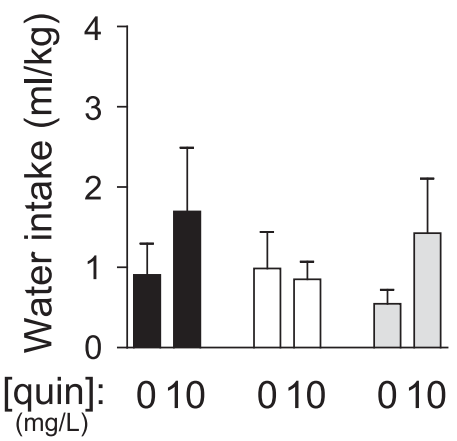

d

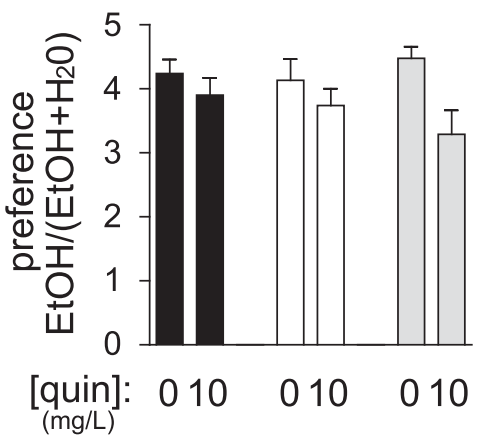

e

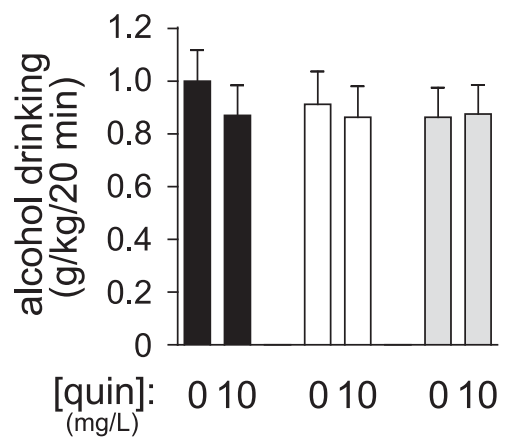

[D-ser]: $0 \quad 50 \quad 100$ $(\mu \mathrm{g})$

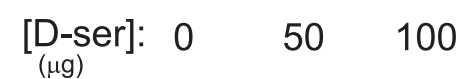

$\underset{(\mathrm{ug})}{\mathrm{D}-\mathrm{ser}]:} \quad 0$

50

100

f

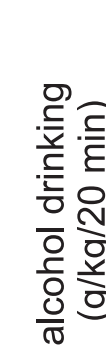

Intra-DLS D-serine$$
1.27
$$

[quin] (mg/L): $0 \quad 10$

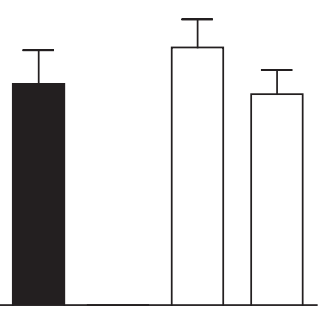

[D-ser] $(\mu \mathrm{g}): 0$

$\begin{array}{ll}0 & 10\end{array}$

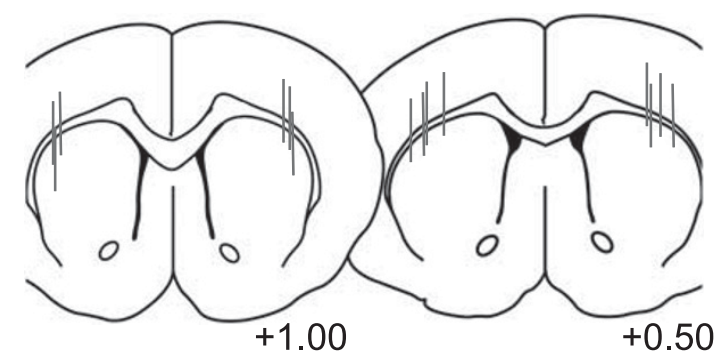

Figure 2 D-serine within the NAcore reduced aversion-resistant alcohol intake. (a) Infusion of D-serine within the NAcore (50 or I00 $\mu \mathrm{g} / \mathrm{side})$ significantly reduced consumption of quinine-adulterated alcohol but not quinine-free alcohol $(n=9)$ (quinine: $F_{1,16}=|3.76|, p=0.006 ; D-s e r i n e: ~ F_{2}, 16=7.543, p=0.005$; interaction: $F_{2,16}=3.917, p=0.041$ ). $* 0<0.05$ for no quinine vs quinine conditions. (b) Histological placement of cannulae targeting the NAcore. Co, NAcore; Sh, NAcb shell. (c, d) Decreased quinine-adulterated alcohol drinking was not accompanied by changes in water intake (c) (all $p>0.1$ ) or alcohol preference (d), although quinine did decrease preference (quinine: $F_{1,16}=13.275, p=0.007$; D-serine: $F_{2,16}=0.444, p=0.788$; interaction: $F_{2,16}=2.173$, $p=0.146$ ). (e) Intra-NAcore $D$-serine did not reduce alcohol intake the day after $D$-serine treatment (all $p>0.3$ ). ( $f$ Infusion of $D$-serine within the DLS $(50 \mu \mathrm{g} / \mathrm{side})$ had no impact on quinine-free or quinine-adulterated alcohol intake $(n=8)$ (all $p>0.15)$. (g) Histology of cannulae targeting the DLS. Numbers in (b) and (g) indicate distance from Bregma. D-ser, D-serine; veh, vehicle.

without the AMPAR blocker DNQX, as in Seif et al (2013). Under these conditions, nearly all current is mediated by AMPARs (Seif et al, 2013), as canonical NMDARs are mostly inactive at hyperpolarized membrane potentials (Cull-Candy and Leszkiewicz, 2004). However, HA-NMDARs, when present, can be detected by a decrease in EPSC amplitude when adding NMDAR blockers such as AP5 (Seif et al, 2013). As HA-NMDAR currents are small, and direct measurement is technically challenging, we used EPSC changes at $-70 \mathrm{mV}$ as a more robust indicator of the presence of HA-NMDARs (Seif et al, 2013).

D-serine $(100 \mu \mathrm{M}$, Chatterton et al, 2002; Junjaud et al, 2006; Wu et al, 1994) significantly reduced mPFC-evoked EPSCs in NAcore neurons from alcohol-drinking rats, with no effect in age-matched, alcohol-naive controls (Figure $3 \mathrm{a}$ and $\mathrm{b}$ ). In contrast, D-serine had no impact on mPFC-ChR2-evoked EPSCs within the DLS (Figure 3c). In addition, we previously showed that NMDAR blockers do 
a

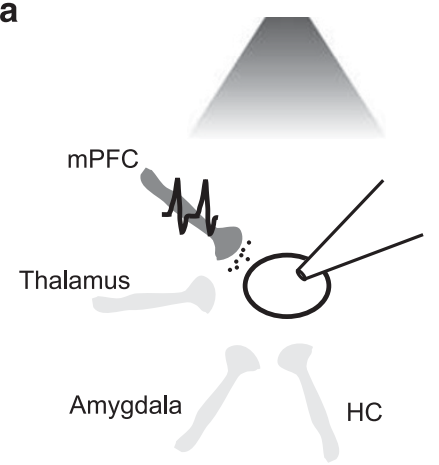

C

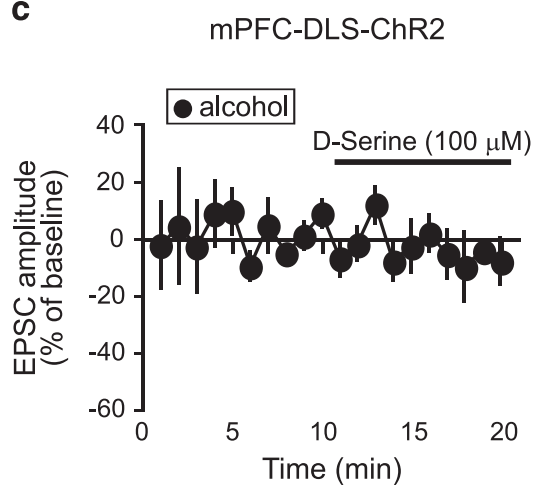

b

mPFC-NAcore-ChR2

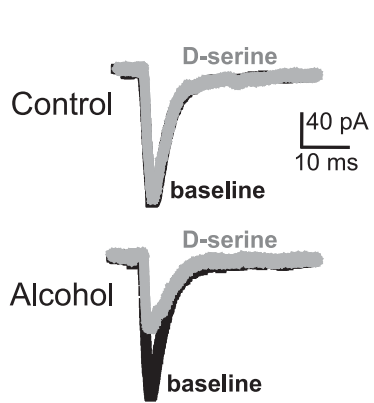

d

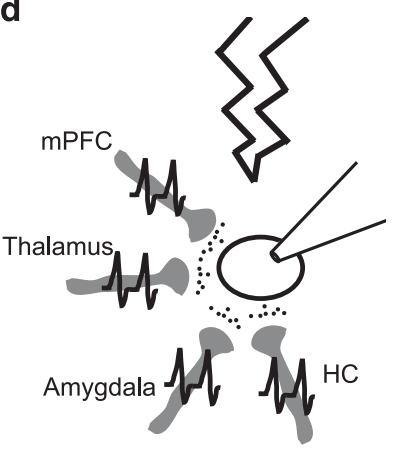

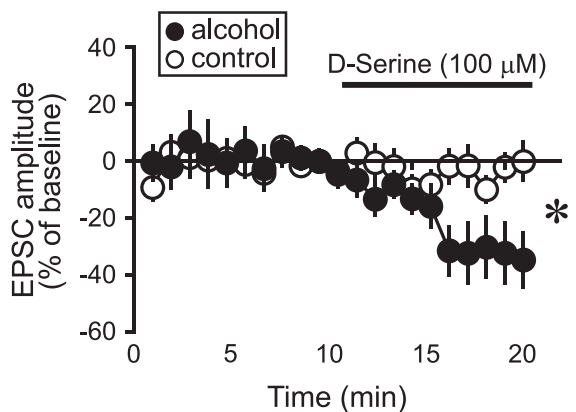

e

NAcore-electrical stim.

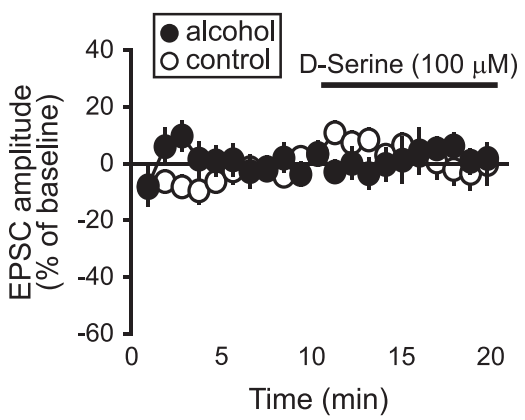

$\mathbf{f}$

D-serine increased NMDAR currents at $\mathrm{Vm}=+40 \mathrm{mV}$
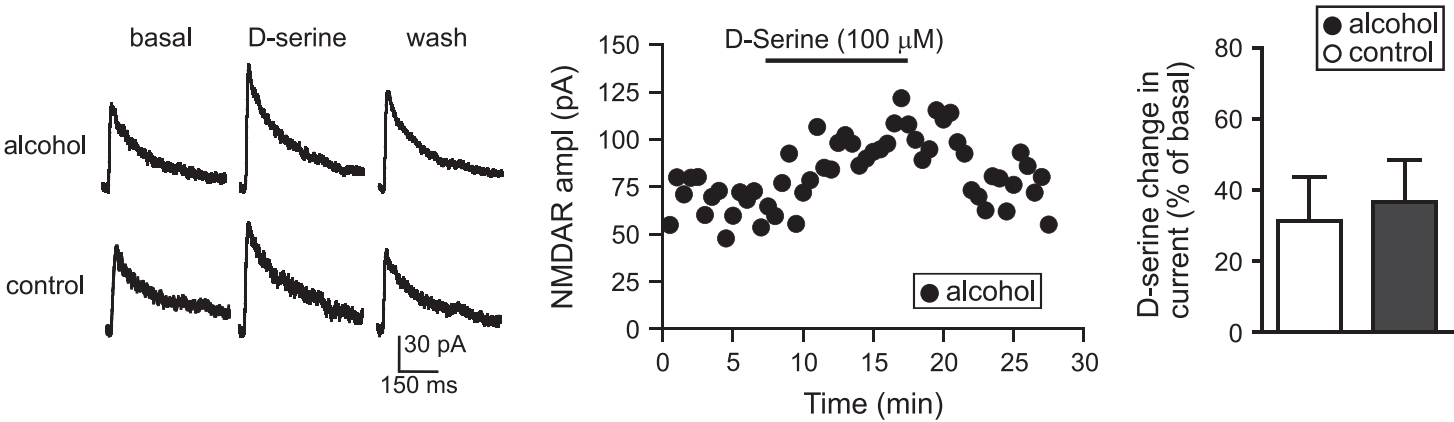

Figure 3 D-serine inhibited EPSCs evoked at $-70 \mathrm{mV}$ under mPFC-NAcore terminals in alcohol-drinking rats. (a) Cartoon showing that a $480 \mathrm{~nm}$ LED only evoked glutamate release (small black circles) from ChR2-filled mPFC terminals within the NAcore (dark gray). HC, hippocampus. (b) Sample traces and grouped data demonstrating that D-serine $(I 00 \mu \mathrm{M})$ significantly reduced mPFC-ChR2-evoked EPSCs at $-70 \mathrm{mV}$ in neurons from alcohol-drinking rats $(n=9$; $-32.9 \pm 10.1 \%$ vs baseline) but not naive rats $(n=8 ;-4.0 \pm 4.2 \%$ vs baseline). Mann-Whitney test, $U=|0 ; p=0.01|$ alcohol vs control, * $p<0.05$ alcohol vs control. (c) D-serine $(I 00 \mu \mathrm{M})$ did not reduce mPFC-evoked EPSCs at $-70 \mathrm{mV}$ in the DLS of alcohol drinkers $\left(n=5 ;-7.4 \pm 6.2 \%\right.$ vs baseline, $t_{4}=1.345$, $p=0.250$ paired t-test). (d) Cartoon showing that electrical stimulation (lightning) evoked glutamate release (small black circles) from terminals originating from all regions (dark gray); only some of the known glutamate inputs to NAcore (Gerfen, 2004) are shown. (e) D-serine did not reduce electrically evoked EPSCs at $-70 \mathrm{mV}$ in NAcore neurons from alcohol-drinking ( $n=6 ; 3.0 \pm 3.3 \%$ vs baseline) or control rats $(n=9 ;-1.8 \pm 5.5 \%$ vs baseline). ( $f$ D-serine enhanced NAcore NMDARs evoked at $+40 \mathrm{mV}$, with no difference between alcohol and control $\left(n=4\right.$ alcohol, 4 control; $\left.t_{6}=0.313, p=0.765\right)$. Ampl, amplitude.

not decrease EPSCs evoked by electrical field stimulation (Seif et al, 2013). Electrical stimulation activates all glutamatergic inputs, whereas HA-NMDARs in alcoholdrinking rats are present only under cortical-NAcore inputs (Seif et al, 2013), which are a small subset of the many glutamatergic inputs onto NAcore neurons (Gerfen, 2004) (Figure 3d). As predicted, D-serine did not alter electrically evoked EPSCs at $-70 \mathrm{mV}$ (Figure 3e). However, D-serine did enhance mPFC-evoked NAcore NMDAR currents at $+40 \mathrm{mV}$ (Figure 3f), showing that
D-serine can exert its canonical action in the NAcore (Curcio et al, 2013), and the D-serine increase in NMDAR currents was not different between alcohol and control neurons (Figure 3f). Smaller D-serine enhancement of $+40 \mathrm{mV}$ NMDAR currents (Figure 3f) relative to that reported for NAc (Curcio et al, 2013) may reflect differences between adult (this study) and juvenile (Curcio et al, 2013). Most importantly, D-serine reduced the amplitude of mPFCNAcore EPSCs evoked at hyperpolarized potentials only in alcohol-drinking rats. 
a mPFC-ChR2

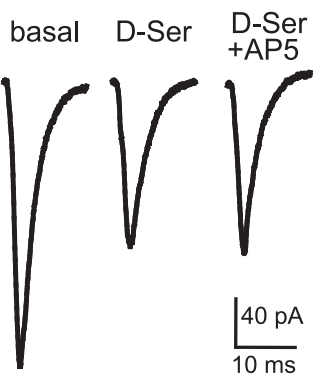

b

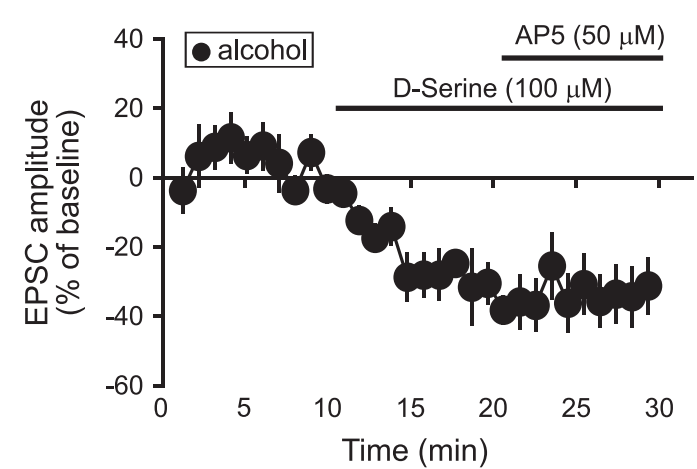

C

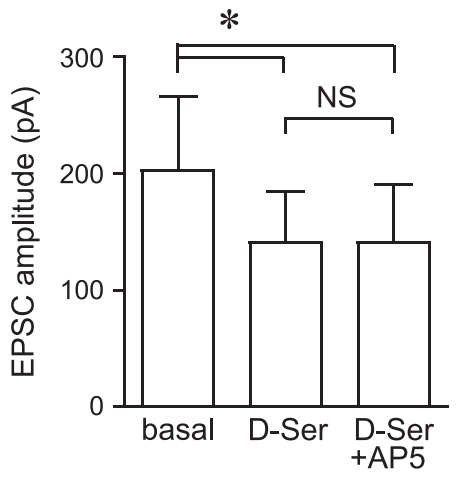

Figure 4 D-serine inhibition of EPSCs occluded the ability of the NMDAR blocker AP5 to inhibit EPSCs. (a) Sample traces and (b, c) grouped data showing that D-serine significantly reduced ChR2-evoked EPSCs evoked at $-70 \mathrm{mV}(-27.9 \pm 6.0 \%$ vs baseline) and, importantly, occluded AP5 from producing any further decrease in EPSCs $(n=6)$, suggesting that D-serine acted by inhibiting HA-NMDARs. $F_{2,10}=10.15, p=0.004$, Friedman repeated-measures ANOVA on ranks, post hoc Holm-Sidak test $* p<0.05$ for baseline vs D-serine or baseline vs D-serine+AP5; NS, for D-serine vs D-serine+AP5. D-ser, D-serine.

To examine whether D-serine reduced mPFC-NACoreevoked EPSCs through inhibition of HA-NMDARs, we investigated whether $\mathrm{D}$-serine could occlude the previously described AP5 inhibition of mPFC-NAcore EPSCs at $-70 \mathrm{mV}$ in alcohol-drinking rats (Seif et al, 2013). D-serine significantly reduced the amplitude of mPFC-evoked EPSC, and adding AP5 after D-serine caused no further inhibition (Figure 4). Also, AP5 alone reduced EPSCs by $-32.4 \pm 8.9 \%$ (data from Seif et al, 2013), whereas AP5 added after D-serine produced no change in EPSCs $(1.2 \pm 10.2 \%$ change $v s$ D-serine; $t_{9}=2.675, p=0.025$ AP5 alone versus AP5 after D-serine). This D-serine occlusion of the effects of AP5 indicates that D-serine reduced mPFC-evoked EPSCs in alcohol-drinking rats by inhibiting HA-NMDARs.

\section{D-Cycloserine Reduced Aversion-Resistant Alcohol Drinking}

DCS is another FDA-approved, glycine-site modulator of NMDARs (Heresco-Levy et al, 2013; Tsai and Lin, 2010), and thus could modulate HA-NMDARs and represent a therapeutic intervention to reduce compulsion-like alcohol drinking. DCS $(10 \mathrm{mg} / \mathrm{kg}$, Moraes Ferreira and Morato, 1997; Torregrossa et al, 2010; Yaka et al, 2007) significantly reduced quinine-resistant alcohol intake, with no impact on quinine-free alcohol drinking (Figure 5a) or consumption of saccharin \pm quinine (Figure 5b). Thus, DCS selectively reduced aversion-resistant alcohol drinking, similar to D-serine (Figures 1 and 2) and other NMDAR inhibitors (Seif et al, 2013), but did not alter concurrent water intake (Figure 5c), alcohol preference (Figure 5d), or alcohol intake the following day (Figure 5e). In addition, in vitro DCS (10 $\mu \mathrm{M}$, Henderson et al, 1990; Rouaud and Billard, 2003) significantly reduced mPFC-ChR2-evoked EPSCs in the NAcore at $-70 \mathrm{mV}$ in alcohol-drinking but not in control rats (Figure 5f) $\left(t_{19}=3.507, p=0.002\right.$ alcohol $v s$ control), with no effect on electrically evoked EPSCs (Figure 5g). These results are similar to those for D-serine and other NMDAR blockers, suggesting that DCS can inhibit HA-NMDARs under mPFC-NAcore inputs in alcoholdrinking rats and, in this way, suppress compulsion-like alcohol intake.

\section{DISCUSSION}

Our results suggest that D-serine and DCS represent novel therapeutic interventions to counteract the aversion-resistant, compulsive drives for alcohol that are a prominent feature of AUDs and a major obstacle to successful treatment. Systemic D-serine and DCS significantly reduced aversion-resistant alcohol intake, with no effect on concurrent water intake or drinking of quinine-free alcohol or saccharin \pm quinine. This suggests that decreased aversion-resistant drinking did not reflect changes in palatability or motor activity, in agreement with no effect of D-serine administered within the NAcore or systemically on locomotor activity or coordination (Curcio et al, 2013; Kretschmer and Schmidt, 1996; Lockridge et al, 2012). A selective effect on aversion-resistant alcohol intake also agrees with the lack of effect of D-serine and DCS on alcohol intoxication (Debrouse et al, 2013), and with our previous results (Seif et al, 2013) and theories proposed by several groups (Naqvi et al, 2014; Tiffany and Conklin, 2000) that conflict-processing cortical regions are recruited during compulsive intake, whereas noncompulsive intake has less requirement for cortical involvement (see Introduction). Importantly, D-serine within the NAcore but not DLS selectively reduced aversion-resistant alcohol drinking, identifying the NAcore as a critical region where D-serine regulates aversion-resistant consumption. Finally, we provide in vitro evidence that D-serine and DCS inhibited NAcore HA-NMDARs in alcohol-drinking rats, similar to other studies where D-serine inhibited HA-NMDARs (Chatterton et al, 2002; Takarada et al, 2009, 2012). D-serine and DCS had no effect on electrically evoked EPSCs, indicating that they did not affect AMPAR EPSCs in general. These results all agree with our previous work showing that NAcore HANMDARs promote aversion-resistant alcohol drinking (Seif et al, 2013), and indicate that D-serine and DCS might be immediately accessible pharmacotherapies for reducing the compulsion to drink alcohol.

Long-term alcohol drinking leads to appearance of HANMDARs under cortical-NAcore inputs that promote aversion-resistant intake (Seif et al, 2013). Several lines of evidence suggest that D-serine inhibits these HA-NMDARs. Both D-serine (this study) and the NMDAR blocker AP5 
a

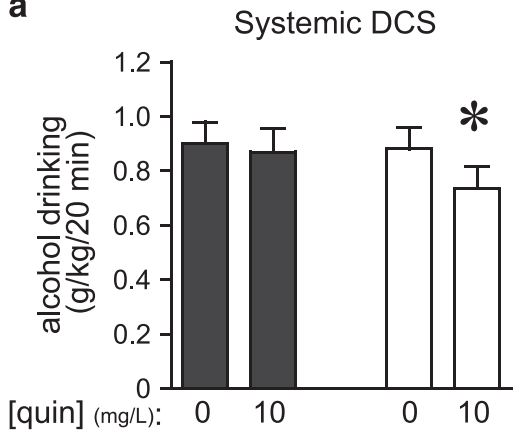

b

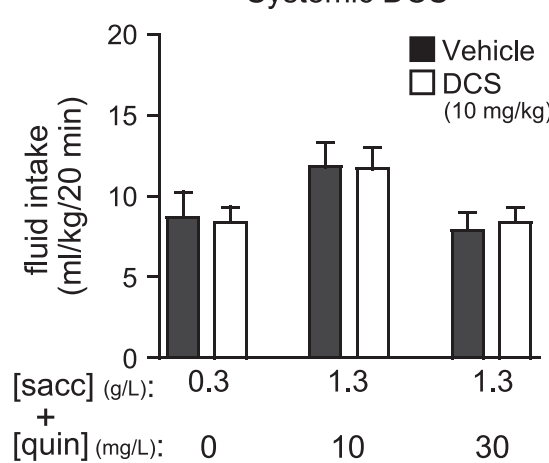

$[\mathrm{DCS}](\mathrm{mg} / \mathrm{kg}): \quad 0$

C

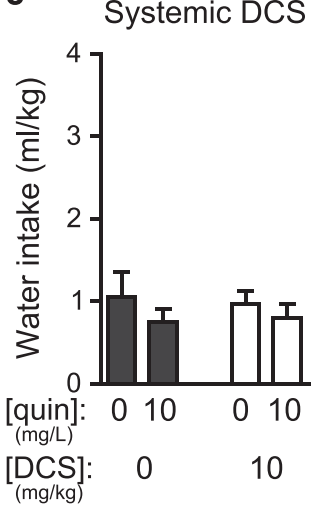

d

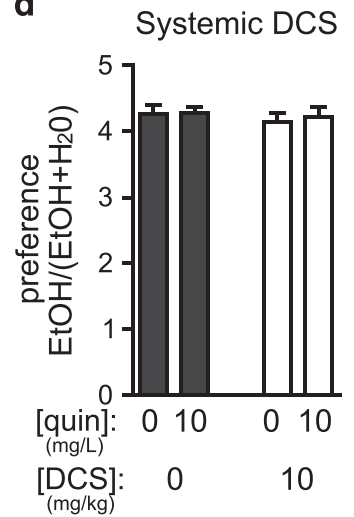

e

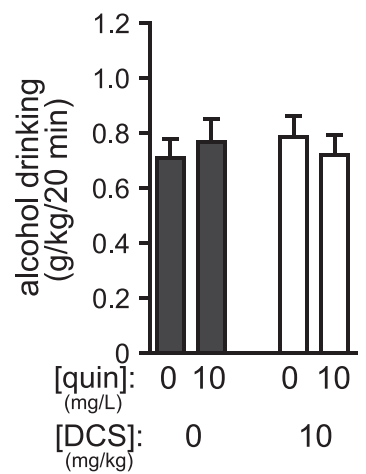

f

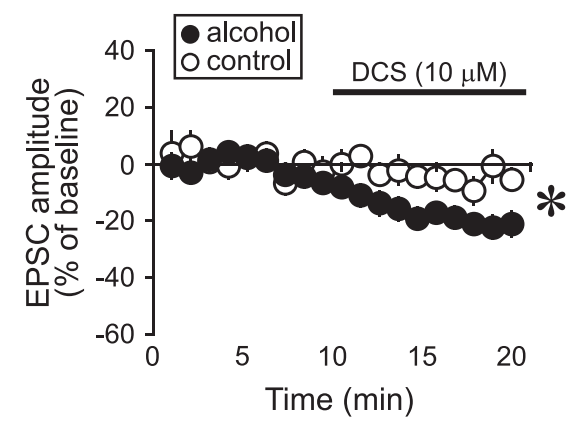

g

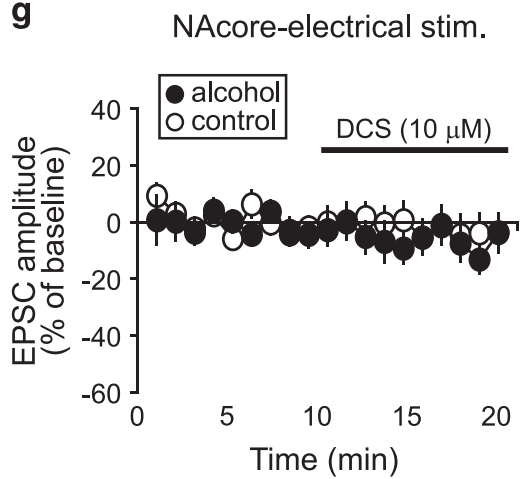

Figure 5 D-cycloserine reduced aversion-resistant alcohol intake and EPSCs evoked at $-70 \mathrm{mV}$ in vitro under mPFC-NAcore terminals. (a) DCS (i.p., $10 \mathrm{mg} / \mathrm{kg}$ ) reduced drinking of quinine-adulterated alcohol but not quinine-free alcohol $\left(n=13\right.$; quinine: $F_{1,12}=3.501, p=0.086 ; D-s e r i n e: F_{1,12}=1.62$, $p=0.162$; interaction: $\left.F_{1,12}=4.811, p=0.049\right)$. ${ }^{*} p<0.05$ for DCS vs all other conditions. (b) Systemic DCS did not alter intake of saccharin \pm quinine ( $n=14$; saccharin-quinine doses: $F_{2,26}=5.78, p=0.008$; D-serine: $F_{1,26}=0.001, p=0.996$; interaction: $\left.F_{2,26}=0.088, p=0.916\right)$. (c-e) DCS reduction of aversionresistant drinking was not accompanied by changes in concurrent water intake (c) (all $p>0.1$ ), alcohol preference (d) (all $p>0.4$ ), or alcohol intake the next day (e) (all $p>0.7)$. (f) DCS ( $10 \mu \mathrm{M}$ ) significantly reduced mPFC-ChR2-evoked EPSCs at $-70 \mathrm{mV}$ in neurons from alcohol-drinking rats $(n=12 ;-21.6 \pm 3.8 \%$ vs baseline) but not naive rats $(n=9 ;-5.2 \pm 3.8 \%$ vs baseline). $* p<0.05$ alcohol vs control. (g) DCS did not reduce electrically evoked EPSCs at $-70 \mathrm{mV}$ in NAcore neurons from alcohol-drinking $(n=7 ;-8.1 \pm 5.5 \%$ vs baseline) or control rats $(n=\mid 4 ;-3.8 \pm 6.4 \%$ vs baseline). Veh, vehicle.

(Seif et al, 2013) within the NAcore reduce aversion-resistant but not quinine-free alcohol drinking. Similarly, both Dserine and DCS (this study) and AP5 (Seif et al, 2013) decrease mPFC-ChR2-evoked EPSCs at $-70 \mathrm{mV}$ in the NAcore of alcohol-drinking rats, with no effect in controls. Importantly, the in vitro D-serine inhibition of mPFCNAcore EPSCs prevented AP5 from further decreasing mPFC-evoked EPSCs; this occlusion indicates that D-serine reduces EPSCs at $-70 \mathrm{mV}$ by inhibiting HA-NMDARs. Although D-serine is an NMDAR activator at the glycine site, it can also inhibit HA-NMDARs containing the GluN3 subunit (Chatterton et al, 2002; Takarada et al, 2009, 2012). Thus, NAcore HA-NMDARs in alcohol drinkers may contain GluN3 in addition to the HA-NMDAR subunit GluN2C described in Seif et al (2013). Furthermore, NMDARs containing only GluN1/3 but not GluN2 subunits are not AP5 sensitive (Smothers and Woodward, 2007), but NAcore HA-NMDARs in alcohol drinkers are blocked by AP5, consistent with the presence of GluN2C (Seif et al, 2013). Also, the $100 \mu \mathrm{M}$ D-serine utilized here in vitro has 
been used for testing effects of saturating concentrations of D-serine at the NMDAR glycine site (Zhang et al, 2008; Curcio et al, 2013), but GluN1/2D/3A HA-NMDARs are inhibited by D-serine only at higher concentrations $(\geq 100 \mu \mathrm{M}$, Takarada et al, 2009, 2012). Similarly, intra-NAcore D-serine can enhance NMDAR function at $4 \mu \mathrm{g}$ (Curcio et al, 2013), but inhibited aversion-resistant alcohol drinking at $50-100 \mu \mathrm{g}$ (Figure 2) but not $25 \mu \mathrm{g}$ (not shown). Although dialysis studies estimate free $\mathrm{D}$-serine in the forebrain at $\sim 6-8 \mu \mathrm{M}$ (Matsui et al, 1995; Ciriacks and Bowser, 2006), basal levels could be several fold higher, and reach hundreds of $\mu \mathrm{M}$ with exogenous D-serine concentrations applied here (Hashimoto and Chiba, 2004; Zhang et al, 2008; Nishikawa, 2011). Together, these results support the idea that NAcore HANMDARs are GluN1/2C/3 heterotrimers. Overall, relatively little is known about such heterotrimers, although GluN2 subunits certainly alter GluN1/3 NMDAR properties (Chatterton et al, 2002; Das et al, 1998; Smothers and Woodward, 2007). Also, although the primary focus of our studies is the possible use of D-serine and DCS to reduce compulsion-like alcohol drinking, and we have demonstrated here that exogenous D-serine significantly and selectively reduced aversion-resistant intake in rats and thus may represent a novel intervention to suppress compulsive aspects of human AUDs, it would be interesting in future experiments to examine possible changes in endogenous $\mathrm{D}$-serine regulation in alcohol-drinking individuals as it could interact with exogenous D-serine.

NMDAR modulators have long been considered as potent therapeutic agents to treat conditions ranging from schizophrenia, depression, and Parkinson's disease to drug and alcohol addiction (D'Ascenzo et al, 2014; Gass and Olive, 2008; Heresco-Levy et al, 2013; Krystal et al, 2003, 2011; Martineau et al, 2014; Sani et al, 2012; Spanagel, 2009; Tsai and Lin, 2010). However, previous studies with NMDAR antagonists have observed somewhat mixed results on alcohol-related behaviors in humans (Gass and Olive, 2008). Memantine, a noncompetitive NMDAR antagonist, has shown promise in some studies (Bisaga and Evans, 2004; Krupitsky et al, 2007; Muhonen et al, 2008) but not others (Evans et al, 2007). Acamprosate reduces alcohol drinking in some individuals, but can act on molecular targets other than NMDARs (Gass and Olive, 2008; Spanagel et al, 2014). D-serine, DCS, and related compounds are of particular interest because of their widespread use and a favorable safety profile, and also the moderate modulatory effects of such compounds that avoids more severe side effects of some NMDAR modulators (Heresco-Levy et al, 2013; Millan, 2005; Tsai and Lin, 2010). We note that nephrotoxicity is a potential concern with long-term, high-dose treatment of D-serine (Krug et al, 2007), but several longer-term D-serine studies have been performed in humans without adverse effects noted (D’Ascenzo et al, 2014; D’Souza et al, 2013; Heresco-Levy et al, 2013; Kantrowitz et al, 2010; Tsai and Lin, 2010). In addition, D-serine and DCS can enhance NMDAR activity and increase memory (Heresco-Levy et al, 2013; Martineau et al, 2014; Sani et al, 2012; Tsai and Lin, 2010). The interaction of this effect with HA-NMDAR inhibition may be complex, but could be synergistic, where D-serine or DCS increases memory for the suppression of compulsive drives for alcohol.
D-serine and DCS reduction of aversion-resistant alcohol intake did not impact alcohol drinking the next day. In agreement, suppressing aversion-resistant intake (by inhibiting mPFC-to-NAcore inputs) did not reduce alcoholquinine intake the following day (Seif et al, 2013). Thus, we consider HA-NMDAR-mediated interventions useful for crisis management to acutely reduce compulsive drives for alcohol as an important part of a more comprehensive therapeutic approach including behavioral therapy and counseling. Also, although we have not directly tested whether D-serine regulates other forms of compulsion-like intake, there are several reasons to consider that it can. Most importantly, a similar cortico-NAcore circuit mediates both quinine-resistant and footshock-resistant alcohol drinking (Seif et al, 2013), and footshock-resistant intake for other rewards such as cocaine has been considered a robust model for aversion-resistant, compulsive aspects of human addiction (Deroche-Gamonet and Piazza, 2014; Everitt and Robbins, 2005). Furthermore, as HA-NMDARs regulate aversion-resistant drinking and are selectively inserted at cortical-NAcore synapses, the HA-NMDAR/cortico-NAcore pathway may represent a common mechanism to promote aversion-resistant alcohol drinking, with no impact on water or saccharin \pm quinine intake. Also, the BAC concentrations observed here (40-50 mg\%, see also Seif et al, 2013; Simms et $a l, 2008)$ were below the level considered for binge intake ( $>80 \mathrm{mg} \%$ ) which perhaps raises questions about the 'compulsivity' of the alcohol drinking we have studied. However, the similar circuit mechanism for quinine-resistant and especially footshock-resistant alcohol intake (Seif et al, 2013) suggests that rats drinking under the intermittent access model exhibited compulsion-like drinking. Our drinking paradigms are designed to examine consumption that persists despite the presence of an aversive consequence; such paradigms have been considered to model compulsive aspects of human AUDs (Everitt and Robbins, 2005; Hopf and Lesscher, 2014; Hopf et al, 2010; Lesscher et al, 2010; Seif et al, 2013; Vengeliene et al, 2009). In addition, the intermittent alcohol-drinking model exhibits other features that may mirror those seen in humans AUDs, including escalation of intake and sensitivity to compounds that can reduce human alcohol drinking (Hopf and Lesscher, 2014; Koob and Volkow, 2010; Simms et al, 2008). Also, other methods of quinine-resistant alcohol drinking with more moderate intake are associated with additional features sometimes observed with human addiction, including disrupted circadian patterns of intake and increased preference for higher concentrations of alcohol (Vengeliene et al, 2009; Wolffgramm et al, 2000). Thus, even with BAC levels of $40-50 \mathrm{mg} \%$, there are many features of the intermittent access to alcohol and aversion-resistant drinking paradigms that provide reasonable confidence that these may model some aspects of pathological human alcohol drinking.

We note that there was an interaction trend (Figure 1e) and main effect of D-serine (Figure 1f) on consumption of saccharin, and thus some of the effect of D-serine on decreasing compulsion-like alcohol drinking may have occurred through nonspecific impacts on fluid intake. Future experiments with a broader range of $\mathrm{D}$-serine doses may clarify this possibility. However, D-serine did not reduce intake of lower concentrations of saccharin+quinine, where drinking volume was more similar to those during alcohol 
intake. Also, DCS systemically had a similar, selective effect on aversion-resistant alcohol drinking as observed with D-serine, with little change in intake of saccharin+quinine, although a limited dose range of DCS was tested. Overall, our results support the possibility that D-serine and DCS selectively inhibited compulsion-like alcohol drinking.

In summary, our results suggest that D-serine and DCS suppressed aversion-resistant alcohol consumption through inhibition of HA-NMDARs within the NAcore. These findings identify D-serine and DCS as novel, immediately accessible and FDA-approved therapeutic interventions to counteract the compulsive aspects of alcohol drinking that represent a major clinical obstacle to successful treatment of AUDs.

\section{FUNDING AND DISCLOSURE}

The authors declare no conflict of interest.

\section{ACKNOWLEDGMENTS}

This study was supported by NIAAA R21AA021445 (to FWH), NIAAA P50AA017072 (to FWH), NIDA F32DA028065 (to TS), and funds provided by the State of California for medical research for alcohol and substance abuse through UCSF (to $\mathrm{AB}$ and $\mathrm{ROM}$ ).

\section{REFERENCES}

Anton RF (2000). Obsessive-compulsive aspects of craving: development of the Obsessive Compulsive Drinking Scale. Addiction 95(Suppl 2): S211-S217.

Bisaga A, Evans SM (2004). Acute effects of memantine in combination with alcohol in moderate drinkers. Psychopharmacology 172: 16-24.

Carnicella S, Amamoto R, Ron D (2009). Excessive alcohol consumption is blocked by glial cell line-derived neurotrophic factor. Alcohol 43: 35-43.

Chatterton JE, Awobuluyi M, Premkumar LS, Takahashi H, Talantova M, Shin Y et al (2002). Excitatory glycine receptors containing the NR3 family of NMDA receptor subunits. Nature 415: 793-798.

Ciriacks CM, Bowser MT (2006). Measuring the effect of glutamate receptor agonists on extracellular D-serine concentrations in the rat striatum using online microdialysis-capillary electrophoresis. Neurosci Lett 393: 200-205.

Cull-Candy SG, Leszkiewicz DN (2004). Role of distinct NMDA receptor subtypes at central synapses. Sci STKE 2004: re16.

Curcio L, Podda MV, Leone L, Piacentini R, Mastrodonato A, Cappelletti $\mathrm{P}$ et al (2013). Reduced D-serine levels in the nucleus accumbens of cocaine-treated rats hinder the induction of NMDA receptor-dependent synaptic plasticity. Brain 136: 1216-1230.

Das S, Sasaki YF, Rothe T, Premkumar LS, Takasu M, Crandall JE et al (1998). Increased NMDA current and spine density in mice lacking the NMDA receptor subunit NR3A. Nature 393: 377-381.

Debrouse L, Hurd B, Kiselycznyk C, Plitt A, Todaro A, Mishina M et al (2013). Probing the modulation of acute ethanol intoxication by pharmacological manipulation of the NMDAR glycine coagonist site. Alcohol Clin Exp Res 37: 223-233.

Deroche-Gamonet V, Piazza PV (2014). Psychobiology of cocaine addiction: contribution of a multi-symptomatic animal model of loss of control. Neuropharmacology 76: 437-449.
D’Ascenzo M, Podda MV, Grassi C (2014). The role of D-serine as co-agonist of NMDA receptors in the nucleus accumbens: relevance to cocaine addiction. Front Synaptic Neurosci 6: 16-21.

D'Souza DC, Radhakrishnan R, Perry E, Bhakta S, Singh NM, Yadav R et al (2013). Feasibility, safety, and efficacy of the combination of $\mathrm{D}$-serine and computerized cognitive retraining in schizophrenia: an international collaborative pilot study. Neuropsychopharmacology 38: 492-503.

Evans SM, Levin FR, Brooks DJ, Garawi F (2007). A pilot doubleblind treatment trial of memantine for alcohol dependence. Alcohol Clin Exp Res 31: 775-782.

Everitt BJ, Robbins TW (2005). Neural systems of reinforcement for drug addiction: from actions to habits to compulsion. Nat Neurosci 8: 1481-1489.

Fiorenza NG, Rosa J, Izquierdo I, Myskiw JC (2012). Modulation of the extinction of two different fear-motivated tasks in three distinct brain areas. Behav Brain Res 232: 210-216.

Gass JT, Olive MF (2008). Glutamatergic substrates of drug addiction and alcoholism. Biochem Pharmacol 75: 218-265.

Gerfen CR (2004). Basal ganglia. In: Paxinos G (ed) The Rat Brain, Elsevier: New York, pp 455-508.

Goodwin FL, Bergeron N, Amit Z (2000). Differences in the consumption of alcohol and flavored solutions in three strains of rats. Pharmacol Biochem Behav 65: 357-362.

Hashimoto A, Chiba S (2004). Effect of systemic administration of $\mathrm{D}$-serine on the levels of D- and L-serine in several brain areas and periphery of rat. Eur J Pharmacol 495: 153-158.

Henderson G, Johnson JW, Ascher P (1990). Competitive antagonists and partial agonists at the glycine modulatory site of the mouse N-methyl-D-aspartate receptor. J Physiol 430: 189-212.

Heresco-Levy U, Shoham S, Javitt DC (2013). Glycine site agonists of the N-methyl-D-aspartate receptor and Parkinson's disease: a hypothesis. Mov Disord 28: 419-424.

Hopf FW, Chang SJ, Sparta DR, Bowers MS, Bonci A (2010). Motivation for alcohol becomes resistant to quinine adulteration after 3-4 months of intermittent alcohol self-administration. Alcohol Clin Exp Res 34: 1565-1573.

Hopf FW, Lesscher HM (2014). Rodent models for compulsive alcohol intake. Alcohol 48: 253-264.

Junjaud G, Rouaud E, Turpin F, Mothet JP, Billard JM (2006). Agerelated effects of the neuromodulator $\mathrm{D}$-serine on neurotransmission and synaptic potentiation in the CA1 hippocampal area of the rat. J Neurochem 98: 1159-1166.

Kantrowitz JT, Malhotra AK, Cornblatt B, Silipo G, Balla A, Suckow $\mathrm{RF}$ et al (2010). High dose D-serine in the treatment of schizophrenia. Schizophr Res 121: 125-130.

Koob GF, Volkow ND (2010). Neurocircuitry of addiction. Neuropsychopharmacology 35: 217-238.

Kretschmer BD, Schmidt WJ (1996). Behavioral effects mediated by the modulatory glycine site of the NMDA receptor in the anterodorsal striatum and nucleus accumbens. J Neurosci 16: 1561-1569.

Krug AW, Völker K, Dantzler WH, Silbernagl S (2007). Why is D-serine nephrotoxic and alpha-aminoisobutyric acid protective? Am J Physiol Renal Physiol 293: F382-F390.

Krupitsky EM, Neznanova O, Masalov D, Burakov AM, Didenko T, Romanova $\mathrm{T}$ et al (2007). Effect of memantine on cue-induced alcohol craving in recovering alcohol-dependent patients. Am J Psychiatry 164: 519-523.

Krystal JH, Petrakis IL, Limoncelli D, Nappi SK, Trevisan L, Pittman B et al (2011). Characterization of the interactive effects of glycine and $\mathrm{D}$-cycloserine in men: further evidence for enhanced NMDA receptor function associated with human alcohol dependence. Neuropsychopharmacology 36: 701-710.

Krystal JH, Petrakis IL, Mason G, Trevisan L, D’Souza DC (2003). $\mathrm{N}$-methyl-D-aspartate glutamate receptors and alcoholism: reward, dependence, treatment, and vulnerability. Pharmacol Ther 99: 79-94. 
Lesscher HM, van Kerkhof LW, Vanderschuren LJ (2010). Inflexible and indifferent alcohol drinking in male mice. Alcohol Clin Exp Res 34: 1219-1225.

Lockridge A, Romero G, Harrington J, Newland B, Gong Z, Cameron A et al (2012). Timing-dependent reduction in ethanol sedation and drinking preference by NMDA receptor co-agonist D-serine. Alcohol 6: 389-400.

Martineau M, Parpura V, Mothet JP (2014). Cell-type specific mechanisms of D-serine uptake and release in the brain. Front Synaptic Neurosci 6: 12.

Matsui T, Sekiguchi M, Hashimoto A, Tomita U, Nishikawa T, Wada K (1995). Functional comparison of D-serine and glycine in rodents: the effect on cloned NMDA receptors and the extracellular concentration. J Neurochem 65: 454-458.

Millan MJ (2005). N-Methyl-D-aspartate receptors as a target for improved antipsychotic agents: novel insights and clinical perspectives. Psychopharmacology 179: 30-53.

Modell JG, Glaser FB, Mountz JM, Schmaltz S, Cyr L (1992). Obsessive and compulsive characteristics of alcohol abuse and dependence: quantification by a newly developed questionnaire. Alcohol Clin Exp Res 16: 266-271.

Moraes Ferreira VM, Morato GS (1997). D-cycloserine blocks the effects of ethanol and HA-966 in rats tested in the elevated plusmaze. Alcohol Clin Exp Res 21: 1638-1642.

Muhonen LH, Lonnqvist J, Juva K, Alho H (2008). Double-blind, randomized comparison of memantine and escitalopram for the treatment of major depressive disorder comorbid with alcohol dependence. J Clin Psychiatry 69: 392-399.

Naqvi NH, Gaznick N, Tranel D, Bechara A (2014). The insula: a critical neural substrate for craving and drug seeking under conflict and risk. Ann NY Acad Sci 1316: 53-70.

Nishikawa T (2011). Analysis of free D-serine in mammals and its biological relevance. J Chromatogr B Analyt Technol Biomed Life Sci 879: 3169-3183.

Roitman MF, Wheeler RA, Carelli RM (2005). Nucleus accumbens neurons are innately tuned for rewarding and aversive taste stimuli, encode their predictors, and are linked to motor output. Neuron 45: 587-597.

Rouaud E, Billard JM (2003). D-cycloserine facilitates synaptic plasticity but impairs glutamatergic neurotransmission in rat hippocampal slices. Br J Pharmacol 140: 1051-1056.

Sani G, Serra G, Kotzalidis GD, Romano S, Tamorri SM, Manfredi $\mathrm{G}$ et al (2012). The role of memantine in the treatment of psychiatric disorders other than the dementias: a review of current preclinical and clinical evidence. CNS Drugs 26: 663-690.

Schwienbacher I, Fendt M, Richardson R, Schnitzler HU (2004). Temporary inactivation of the nucleus accumbens disrupts acquisition and expression of fear-potentiated startle in rats. Brain Res 1027: 87-93.

Seif T, Chang SJ, Simms JA, Gibb SL, Dadgar J, Chen BT et al (2013). Cortical activation of accumbens hyperpolarization-active
NMDARs mediates aversion-resistant alcohol intake. Nat Neurosci 16: 1094-1100.

Simms JA, Steensland P, Medina B, Abernathy KE, Chandler LJ, Wise R, Bartlett SE (2008). Intermittent access to $20 \%$ ethanol induces high ethanol consumption in Long-Evans and Wistar rats. Alcohol Clin Exp Res 32: 1816-1823.

Smothers CT, Woodward JJ (2007). Pharmacological characterization of glycine-activated currents in HEK 293 cells expressing $\mathrm{N}$-methyl-D-aspartate NR1 and NR3 subunits. J Pharmacol Exp Ther 322: 739-748.

Spanagel R (2009). Alcoholism: a systems approach from molecular physiology to addictive behavior. Physiol Rev 89: 649-705.

Spanagel R, Vengeliene V, Jandeleit B, Fischer WN, Grindstaff K, Zhang X, Gallop MA, Krstew EV, Lawrence AJ, Kiefer F (2014). Acamprosate produces its anti-relapse effects via calcium. Neuropsychopharmacology 39: 783-791.

Takarada T, Takahata Y, Iemata M, Hinoi E, Uno K, Hirai T et al (2009). Interference with cellular differentiation by D-serine through antagonism at $\mathrm{N}$-methyl-D-aspartate receptors composed of NR1 and NR3A subunits in chondrocytes. J Cell Physiol 220: 756-764.

Takarada T, Takarada-Iemata M, Takahata Y, Yamada D, Yamamoto T, Nakamura Y et al (2012). Osteoclastogenesis is negatively regulated by D-serine produced by osteoblasts. J Cell Physiol 227: 3477-3487.

Tiffany ST, Conklin CA (2000). A cognitive processing model of alcohol craving and compulsive alcohol use. Addiction 95(Suppl 2): S145-S153.

Torregrossa MM, Sanchez H, Taylor JR (2010). D-cycloserine reduces the context specificity of pavlovian extinction of cocaine cues through actions in the nucleus accumbens. J Neurosci 30: 10526-10533.

Tsai GE, Lin PY (2010). Strategies to enhance N-methyl-D-aspartate receptor-mediated neurotransmission in schizophrenia, a critical review and meta-analysis. Curr Pharm Des 16: 522-537.

Vengeliene V, Celerier E, Chaskiel L, Penzo F, Spanagel R (2009). Compulsive alcohol drinking in rodents. Addict Biol 14: 384-396.

Wolffgramm J, Galli G, Thimm F, Heyne A (2000). Animal models of addiction: models for therapeutic strategies? J Neural Transm 107: 649-668.

Wu HQ, Schwarcz R, Shepard PD (1994). Excitatory amino acidinduced excitation of dopamine-containing neurons in the rat substantia nigra: modulation by kynurenic acid. Synapse 16: 219-230.

Yaka R, Biegon A, Grigoriadis N, Simeonidou C, Grigoriadis S, Alexandrovich AG et al (2007). D-cycloserine improves functional recovery and reinstates long-term potentiation (LTP) in a mouse model of closed head injury. FASEB J 21: 2033-2041.

Zhang Z, Gong N, Wang W, Xu L, Xu TL (2008). Bell-shaped $\mathrm{D}$-serine actions on hippocampal long-term depression and spatial memory retrieval. Cereb Cortex 18: 2391-2401. 